\title{
Bidirectional Modulation of Alcohol-Associated Memory Reconsolidation through Manipulation of Adrenergic Signaling
}

\author{
Moritz JW Schramm', Barry J Everitt' and Amy L Milton*,I \\ 'Department of Psychology, University of Cambridge, Cambridge, UK
}

\begin{abstract}
Alcohol addiction is a problem of great societal concern, for which there is scope to improve current treatments. One potential new treatment for alcohol addiction is based on disrupting the reconsolidation of the maladaptive Pavlovian memories that can precipitate relapse to drug-seeking behavior. In alcohol self-administering rats, we investigated the effects of bidirectionally modulating adrenergic signaling on the strength of a Pavlovian cue-alcohol memory, using a behavioral procedure that isolates the specific contribution of one maladaptive Pavlovian memory to relapse, the acquisition of a new alcohol-seeking response for an alcohol-associated conditioned reinforcer. The $\beta$-adrenergic receptor antagonist propranolol, administered in conjunction with memory reactivation, persistently disrupted the memory that underlies the capacity of a previously alcohol-associated cue to act as a conditioned reinforcer. By contrast, enhancement of adrenergic signaling by administration of the adrenergic prodrug dipivefrin at reactivation increased the strength of the cue-alcohol memory and potentiated alcohol seeking. These data demonstrate the importance of adrenergic signaling in alcohol-associated memory reconsolidation, and suggest a pharmacological target for treatments aiming to prevent relapse through the disruption of maladaptive memories.
\end{abstract}

Neuropsychopharmacology (20 I6) 4I, I I03-I I II; doi: I0. I038/npp.20 I5.248; published online I6 September 2015

\section{INTRODUCTION}

Memory reconsolidation-the process by which memories are destabilized following retrieval, and subsequently restabilized to persist in the brain-has received much attention for its potential utility in the development of treatments for neuropsychiatric disorders in which maladaptive emotional memories play a key role (Diergaarde et al, 2008; Milton and Everitt, 2010; Milton, 2013; Torregrossa and Taylor, 2013). One such disorder is drug addiction; this chronic relapsing disorder, in which individuals lose control of their drug use, is characterized by a sustained risk of relapse during abstinence (Tiffany, 1990; Anthony et al, 1994). Relapse to drug use can be influenced by a number of factors, including a drinking lapse, ie, druginduced reinstatement (de Wit, 1996; Lê et al, 1998), stress (Erb et al, 1996; Shaham and Stewart, 1996; Lê et al, 1998) and, importantly, for the current work, environmental cues that have previously been associated with drug use in a Pavlovian manner (de Wit and Stewart, 1981). These Pavlovian conditioned stimuli (CSs) that precipitate relapse to drug-seeking behavior activate maladaptive emotional memories and elicit craving and drug-seeking; thus, disrupting their reconsolidation by the administration of

\footnotetext{
*Correspondence: Dr AL Milton, Department of Psychology, University of Cambridge, Downing Site, Cambridge CB2 3EB, UK, Tel: +44 1223 333593, Fax: +44 1223 333564, E-mail: alm46@cam.ac.uk

Received 16 April 20 I5; revised 23 July 2015 ; accepted 12 August 20 I5; accepted article preview online 17 August 2015
}

an appropriate amnestic agent could be a useful therapeutic strategy.

One such amnestic agent that has received attention is the $\beta$-adrenergic receptor antagonist propranolol. It has long been known that the adrenergic system influences the consolidation of emotional memories, with an enhancement of signaling at adrenergic receptors increasing memory strength (Sternberg et al, 1985; Introini-Collison and McGaugh, 1986; Sternberg et al, 1986; Crowe et al, 1990; Ferry et al, 1999; Hatfield and McGaugh, 1999) and the administration of antagonists at these receptors impairing memory consolidation (Sternberg et al, 1985; Sternberg et al, 1986; Introini-Collison et al, 1992; Hatfield and McGaugh, 1999). These effects, in addition to those on synaptic plasticity in vivo (Bliss et al, 1983; Dahl et al, 1983) and in slice preparations (Stanton and Sarvey, 1985; Ferry et al, 1997) led to the adrenergic system being one of the first targets of investigation in the field of memory reconsolidation. Following early demonstrations that antagonism at $\beta$-adrenergic receptors could disrupt the reconsolidation of memories underlying auditory conditioned fear in rats (Dębiec and LeDoux, 2004), it was demonstrated that $\beta$-adrenergic receptor antagonism with propranolol also disrupted the reconsolidation of drug-associated memories in cocaine-conditioned (Fricks-Gleason and Marshall, 2008) and morphine-conditioned (Robinson and Franklin, 2007; Robinson and Franklin, 2010) place preference procedures, and in procedures investigating the capacity of previously cocaine-associated cues to elicit and maintain drug seeking (Milton et al, 2008). However, these effects have not been 
universally replicated, as the memories underlying place preference in chronically morphine-treated rats appear insensitive to propranolol at reactivation (Robinson et al, 2011).

The reconsolidation of alcohol-associated memories has been less well-studied than for other drugs of abuse, despite alcohol abuse and addiction presenting a significant societal burden (UK Home Office, 2012). Memories relevant to relapse in alcohol addiction do appear to undergo reconsolidation (von der Goltz et al, 2009; Wouda et al, 2010; Barak et al, 2013), but there have been inconsistent reports in the literature regarding the dependence of this process on $\beta$-adrenergic signaling. Those few studies that have investigated the effects of propranolol on alcohol-associated memories have shown that propranolol does not disrupt the reconsolidation of the memories underlying alcoholconditioned place preference (Font and Cunningham, 2012), but does disrupt the reconsolidation of Pavlovian memories that contribute to cue-induced relapse to alcohol seeking (Wouda et al, 2010). As cue-induced relapse can be behaviorally deconstructed into the constituent processes of Pavlovian conditioned approach, conditioned motivation, and conditioned reinforcement (the 'three routes to relapse'-see Milton and Everitt, 2010), this latter report appears to be inconsistent with the finding that propranolol does not disrupt the reconsolidation of the memories underlying Pavlovian conditioned approach or conditioned motivation for alcohol-associated cues (Milton et al, 2012). However, this may reflect differential dependence of the reconsolidation of the memories underlying these processes on $\beta$-adrenergic signaling. Propranolol has also been shown ineffective at disrupting the reconsolidation of the memories underlying Pavlovian conditioned approach and conditioned motivation for sucrose-associated cues (Lee and Everitt, 2008), yet it impairs the reconsolidation of the memory allowing a sucrose-associated cue to act as a conditioned reinforcer (Milton et al, 2008). It has also been shown previously that manipulations that fail to impair the reconsolidation of the memories underlying conditioned place preference may disrupt the memories that underlie conditioned reinforcement (Théberge et al, 2010). Thus, a key question is whether $\beta$-adrenergic signaling is required for the reconsolidation of the Pavlovian memory underlying the capacity of a previously alcohol-associated cue to act as a conditioned reinforcer; if it is, then this may provide an explanation for why propranolol disrupts the reconsolidation of the memories underlying some, but not all, measures of relapse to alcohol seeking.

Therefore, in this study, we investigated the effects of adrenergic manipulations on the reconsolidation of an alcohol-associated cue memory and its capacity to act as a conditioned reinforcer. We hypothesized that adrenergic transmission within the brain would be required for the restabilization of a cue-alcohol memory, and its ability to act subsequently as a conditioned reinforcer. We tested this hypothesis using the acquisition of a new instrumental seeking response for conditioned reinforcement (ANR), and by comparing the effects of administering at reactivation the lipophilic $\beta$-adrenergic receptor antagonist propranolol $v s$ the hydrophilic (lipophobic) $\beta$-adrenergic receptor antagonist nadolol, which does not cross the blood-brain barrier. We further hypothesized that an enhancement of adrenergic signaling would enhance the reconsolidation of an alcoholassociated cue memory, thereby potentiating its impact on alcohol seeking; we tested this hypothesis in a separate experiment by administering the adrenergic prodrug dipivefrin (Kaback et al, 1976) before memory reactivation.

\section{MATERIALS AND METHODS}

\section{Subjects}

Subjects were 113 experimentally naive male Lister-Hooded rats (Charles River, Bicester, UK) housed in pairs in a vivarium on a reversed light-dark cycle (lights on at 19:00) and weighing between $201-337 \mathrm{~g}$ at the start of the experiments. Subjects were food restricted, although not deprived, and maintained at least $90 \%$ of their free-feeding weight. Animals were fed after training or testing each day. Access to water was ad libitum except for when inside the conditioning chambers, and for the first 2 days of saccharin fading, when animals were water restricted (without food restriction) for $22 \mathrm{~h}$ per day. All procedures were conducted in accordance with the UK Animals (Scientific Procedures) Act 1986.

\section{Habituation to Ethanol Drinking (Saccharin-Fading Procedure)}

Rats were habituated to ethanol drinking using a modified version of the sucrose fading procedure, as described previously (Milton et al, 2012). Briefly, they were placed in individual cages containing a single bottle, and were given 1-h long access sessions daily for a total of 14 days. The fluid contained in the bottle varied across sessions: four sessions of $0.2 \%$ saccharin, followed by two sessions of $0.2 \%$ saccharin $+5 \%$ ethanol, then two sessions of $5 \%$ ethanol, two sessions of $0.2 \%$ saccharin $+8 \%$ ethanol, two sessions of $8 \%$ ethanol, and finally two sessions of $0.2 \%$ saccharin $+10 \%$ ethanol (Supplementary Figure S1). Fluid intake in milliliters was estimated by weighing the bottles before and after each session. Following habituation to ethanol drinking, all animals progressed on to ethanol self-administration training.

\section{Behavioral Procedures}

In order to assess the integrity of the CS-ethanol memory following our experimental manipulations at reactivation, we used the acquisition of a new instrumental response (ANR) procedure (as used to investigate the reconsolidation of cocaine- and sucrose-associated memories in Milton et al, 2008) to assess whether the previously ethanol-associated CS was able subsequently to act as a conditioned reinforcer (Figures 1a and 2a). Briefly, in the first phase of the experiment animals were trained to self-administer ethanol with an instrumental response (a nosepoke), which led to the simultaneous presentation of a light, the pavlovian CS. Following the experimental manipulations of memory at reactivation, animals were tested repeatedly in the second phase of the experiment for the acquisition of a novel instrumental response (lever pressing) for the presentation of the CS alone. Pavlovian CSs that are capable of acting as conditioned reinforcers, because of their previous association 
a

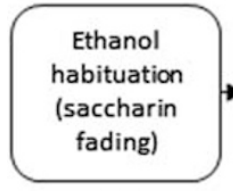

$x 14$

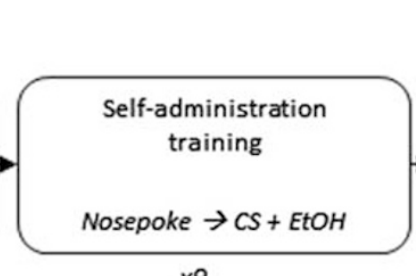

$\times 9$

b

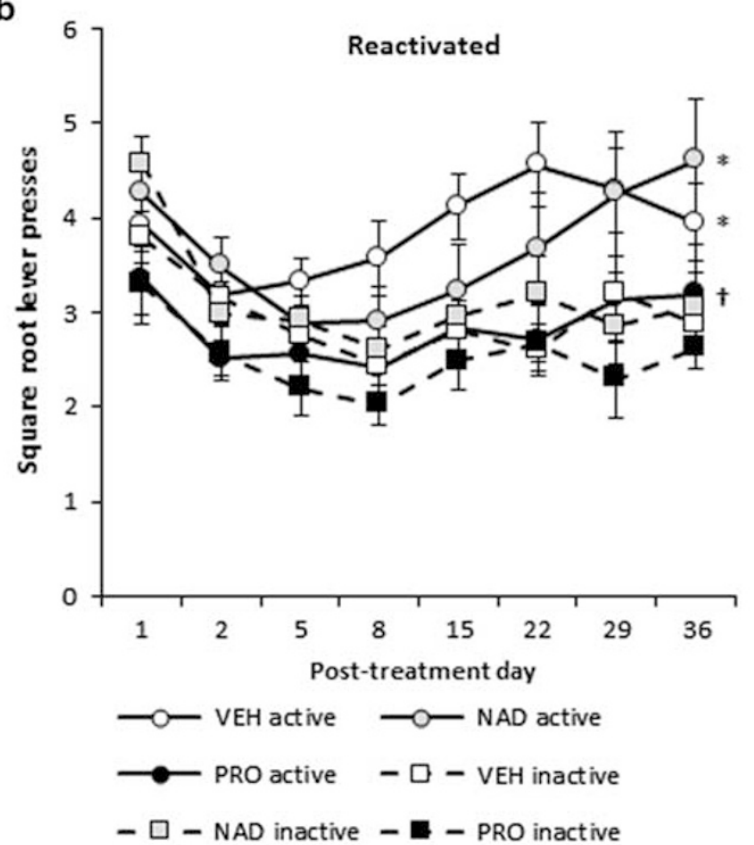

d

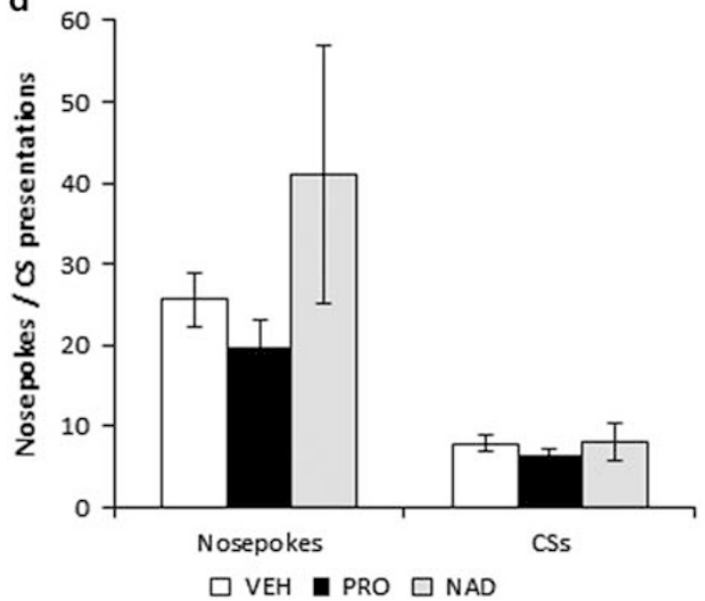

C

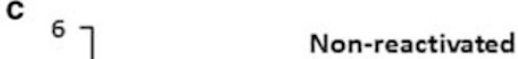

Acquisition of a new response for conditioned reinforcement

Active lever $\rightarrow C S$; Inactive lever $\rightarrow \varnothing$

$\times 8$

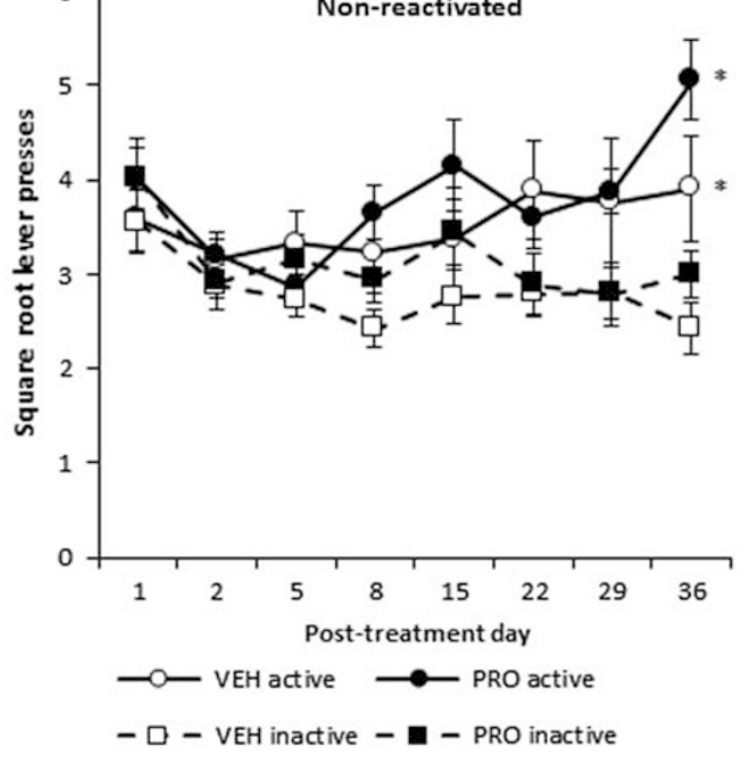

Figure I A centrally active, but not peripherally active, $\beta$-adrenergic receptor antagonist disrupted the reconsolidation of a CS-alcohol memory. (a) An overview of the experimental timeline. The injection symbol represents an i.p. injection of the centrally active $\beta$-adrenergic receptor antagonist propranolol (PRO), the peripherally active $\beta$-adrenergic receptor antagonist nadolol (NAD) or vehicle (VEH) 30 min before the memory reactivation session. The numbers underneath the boxes refer to the number of sessions. (b) Administration of PRO before memory reactivation prevented a previously alcoholassociated CS from subsequently acting as a conditioned reinforcer. By contrast, administration of NAD at reactivation did not affect the CS-alcohol memory, such that the CS could subsequently act as a conditioned reinforcer in the same manner that it did for animals treated with VEH at reactivation. Asterisks denote statistically higher responding on the active than inactive lever, the dagger denotes active lever pressing that is significantly lower than the VEH control group. (c) When PRO was administered without a memory reactivation session, it did not subsequently impair the capacity of the alcohol-associated CS to act as a conditioned reinforcer, indicating that the disruption of the CS-alcohol memory with propranolol was reactivation-dependent. Asterisks denote statistically higher responding on the active than inactive lever. Data in $b$ and $c$ are square-root transformed and presented as means \pm SEM. (d) The administration of $\beta$-adrenergic receptor antagonists had no acute effect on performance during the memory reactivation session, as PRO nor NAD had any effect on the number of nosepokes made during the memory reactivation, or the number of response-contingent CS presentations earned during this session. Group sizes: $(b$ and $d$ ) reactivated $\mathrm{VEH}=22$; reactivated $\mathrm{PRO}=1 \mathrm{I}$; reactivated $\mathrm{NAD}=9$; $(\mathrm{c})$ non-reactivated $\mathrm{VEH}=13$; non-reactivated $\mathrm{PRO}=13$ rats per group. 
a

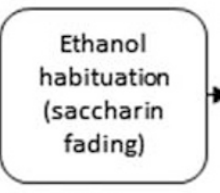

$x 14$

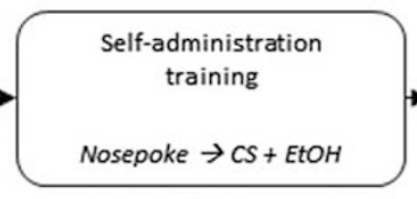

$x 9$

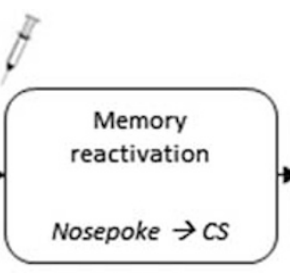

$x 1$
Acquisition of a new response for conditioned reinforcement

Active lever $\rightarrow C S$; Inactive lever $\rightarrow \varnothing$ b

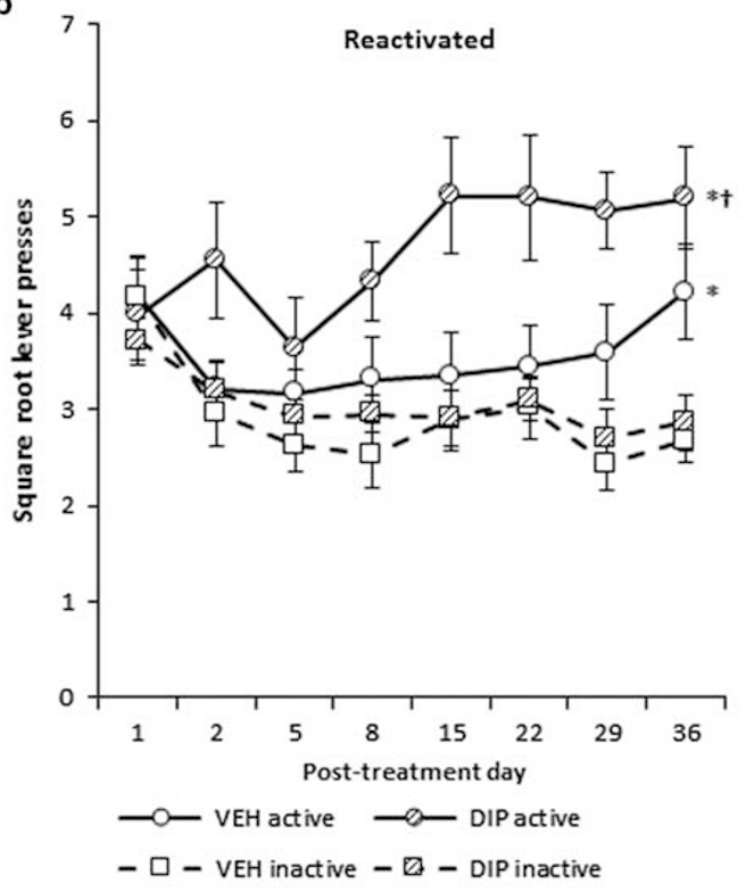

C

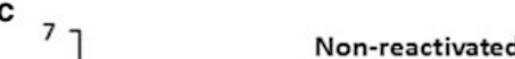

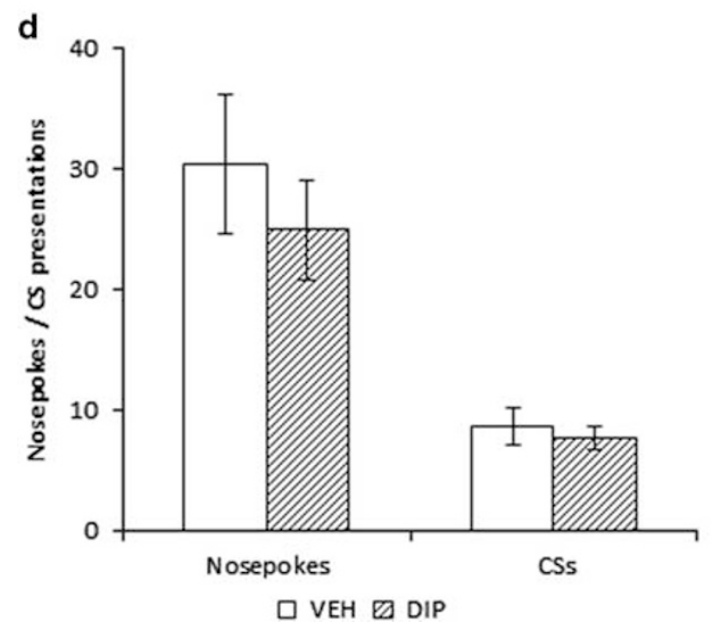

Figure 2 Administration of the adrenergic prodrug dipivefrin (DIP) enhanced the reconsolidation of CS-alcohol memory, increasing subsequent responding for a previously alcohol-associated conditioned reinforcer. (a) An overview of the experimental timeline. The injection symbol represents an i.p. injection of the adrenergic prodrug DIP 10 min before the memory reactivation session. The numbers underneath the boxes refer to the number of sessions. (b) Administration of DIP before the memory reactivation session enhanced subsequent responding on the lever reinforced by presentation of the previously alcohol-associated conditioned reinforcer. Asterisks denote statistically higher responding on the active than inactive lever; the dagger denotes active lever pressing that is significantly higher than the VEH control group. (c) DIP given without memory reactivation produced subsequent responding that was indistinguishable from vehicle-treated animals. Asterisks denote statistically higher responding on the active than inactive lever. Data in b and $\mathrm{c}$ are square-root transformed and presented as means \pm SEM. (d) DIP had no acute effect on performance during the memory reactivation session, as it did not affect the number of nosepoke responses made, or CS presentations earned, relative to the vehicle-treated (VEH) control group during the memory reactivation session. Group sizes: ( $b$ and $d$ ) reactivated $\vee E H=\mid 3$; reactivated $D I P=\mid 4$; (c) non-reactivated $V E H=9$; nonreactivated $\mathrm{DIP}=9$ rats per group. 
with the ethanol reinforcer, support the acquisition of a new instrumental response, while CSs that are not (or are no longer) associated with primary reinforcement cannot. Thus, the ANR procedure provides a stringent assay for a specific psychological process that can only be supported when the CS-ethanol memory is intact.

All behavioral procedures were conducted during the animals' dark cycle. Rats were trained in conditioning chambers (Med Associates Inc., St Albans, Vermont) to make a nosepoke response into a central magazine for presentation of a $0.1 \mathrm{ml}$ of a $10 \%(\mathrm{v} / \mathrm{v})$ ethanol reinforcer (Sigma-Aldrich, Gillingham, UK), which was associated with a 20-s light CS (presented on the same side assigned to the 'inactive' lever during testing, counterbalanced across rats) on a fixed ratio (FR) 1 schedule. Rats were trained over nine sessions, with the session terminating after $60 \mathrm{~min}$ or a maximum of $30 \mathrm{CS}$-ethanol pairings per session, whichever occurred first.

The day after the completion of training, rats received systemic injections of drugs targeting the adrenergic system 30 min before the memory reactivation session. During this session, nosepokes led to the presentation of the light CS and activation of the pump that delivered ethanol during training on an FR1 schedule, but no ethanol was delivered. The primary reinforcer was omitted at reactivation because it has been hypothesized (Pedreira et al, 2004) and is becoming increasingly supported (Forcato et al, 2009; Sevenster et al, 2013) that memory destabilization processes are initiated by a 'mismatch' between what is expected by the individual and what occurs during the reactivation session. For this reason, the session also terminated 'early', after $15 \mathrm{~min}$. During this time, the rats were limited to a maximum of $30 \mathrm{CS}$ presentations, but this limit was not usually reached (see Figures $1 \mathrm{~d}$ and $2 \mathrm{~d}$ for the number of CS presentations achieved).

Testing began $24 \mathrm{~h}$ after the memory reactivation session. The rats were returned to the same conditioning chambers, but in this phase they were presented with two novel levers (left and right of the central magazine). Depression of the 'active' lever led to an abbreviated (1 s) presentation of the light CS on a variable ratio schedule (VR1-3), while depression of the 'inactive' lever had no programmed consequence and acted as a control for general activity. The light CS was always presented on the side opposite to the 'active' lever, to avoid Pavlovian conditioned approach contributing to lever pressing. No ethanol was available during these sessions. Rats were returned to the chambers for eight 30-min sessions, conducted 1, 2, 5, and 8 days following memory reactivation, and then weekly following day 8 (on days $15,22,29$, and 36). Lever presses and nosepokes were recorded by computer.

\section{Systemic Drug Administration}

Experiment 1 -the effects of centrally active vs peripherally active $\beta$-adrenergic receptor antagonists on the reconsolidation of a CS-alcohol memory. All rats received intraperitoneal (i.p.) injections of the lipophilic $\beta$-adrenergic receptor antagonist propranolol (PRO, $10 \mathrm{mg} / \mathrm{kg}$; Sigma-Aldrich), the hydrophilic $\beta$-adrenergic receptor antagonist nadolol (NAD, $20 \mathrm{mg} / \mathrm{kg}$; Sigma-Aldrich), or saline vehicle (VEH). Animals that underwent memory reactivation were injected i.p. in a novel room and returned to the home cage for $30 \mathrm{~min}$ before the memory reactivation session; non-reactivated control groups received injections in the novel room and were not re-exposed to the conditioning chambers. The dose of propranolol used has been shown previously to disrupt the reconsolidation of Pavlovian CS fear (Dębiec and LeDoux, 2004) and Pavlovian CS-sucrose (Milton et al, 2008) memories. Although nadolol is reported to have higher efficacy at $\beta$-adrenergic receptors than propranolol (Escoubet et al, 1986) a higher dose of nadolol was used here to ensure that a behaviorally effective dose was used, and to be consistent with previous literature (Robinson and Franklin, 2007).

Experiment 2-the effects of the adrenergic prodrug dipivefrin on the reconsolidation of a CS-alcohol memory. Animals received i.p. injections of either the adrenergic prodrug dipivefrin (DIP) hydrochloride $(10 \mu \mathrm{g} / \mathrm{kg}$, US Pharmacopeial Convention, Rockville, MD, USA) or its saline vehicle (VEH) 10 min before the memory reactivation session. This dose of DIP has been shown to enhance the consolidation of inhibitory avoidance memory when administered immediately after training (Introini-Collison et al, 1992). Non-reactivated animals received the same dose of DIP but were returned to the home cage after the injection.

\section{Sample Size, Statistical Power, and Randomization}

A priori sample size calculations were not conducted but the number of subjects per group was chosen by reference to previous research. Data were collected over an extended period of time, with 6-8 animals being run within a single squad. Data from different squads were pooled for analysis, with final numbers per group of: (experiment 1) reactivated $\mathrm{VEH}=22$, reactivated $\mathrm{PRO}=11$, reactivated $\mathrm{NAD}=9$, nonreactivated $\mathrm{VEH}=13$, and non-reactivated $\mathrm{PRO}=13$; (experiment 2) reactivated $\mathrm{VEH}=13$, reactivated $\mathrm{DIP}=14$, non-reactivated $\mathrm{VEH}=9$, and non-reactivated $\mathrm{DIP}=9$. Subjects were pseudorandomly assigned to experimental groups, such that drug assignments were made according to training performance (ie, groups were matched for nosepoking performance and the numbers of CSs and ethanol reinforcers earned during training).

\section{Data Collection and Statistical Analysis}

Data were recorded automatically by the Conditioned Reinforcement program (Cardinal, 2005) running within the Whisker Control server (Cardinal, 2000). As the data were collected by computer, blinding to experimental group was not required.

Training and testing data were analyzed using repeated measures ANOVA, and reactivation data were analyzed using a one-way ANOVA. The normality assumption of ANOVA was checked with the Shapiro-Wilk test, and if this indicated that the data were not normally distributed, then they were transformed. The lever pressing and nosepoke data from the ANR phase of the experiment were not normally distributed, so were transformed using the Box-Cox method with $\lambda=0.5$; ie, square-root transformed. Following this transformation, the majority of the lever press data satisfied the assumption of normality $(p>0.05)$. 
If Mauchly's test indicated that the assumption of sphericity had been violated, then the Greenhouse-Geisser correction was applied where $\varepsilon<0.75$, and the Huynh-Feldt correction applied where $\varepsilon>0.75$, as recommended by Cardinal and Aitken (2006). The $\alpha$-level was 0.05 for all analyses, and $p$-values are two-tailed. Where appropriate, subsequent ANOVAs and Šidák-corrected pairwise comparisons were conducted to investigate specific a priori hypotheses.

\section{RESULTS}

\section{Experiment 1}

Administration of the lipophilic $\beta$-adrenergic receptor antagonist propranolol, but not the hydrophilic $\beta$-adrenergic receptor antagonist nadolol, before memory reactivation disrupted the CS-alcohol memory that subsequently supports conditioned reinforcement. Administration of the lipophilic $\beta$-adrenergic receptor antagonist propranolol before memory reactivation impaired the capacity of a previously alcohol-associated CS to act as a conditioned reinforcer, in a reactivation-dependent manner (Figure 1b; drug $\times$ reactivation: $F_{(1,55)}=5.46, p=0.023, \eta^{2}=0.09$ ). Animals that received VEH readily acquired the new instrumental response, increasing responding on the active lever across the eight test sessions (lever: $\mathrm{F}_{(1,33)}=17.9, p<0.001$, $\eta^{2}=0.35$; lever $\times$ session: $\mathrm{F}_{(5.4,180)}=4.99, p<0.001, \eta^{2}=0.13$ ) with no differences in performance between reactivated (Figure 1b) and non-reactivated (Figure 1c) groups (reactivation: $\mathrm{F}<1$; lever $\times$ reactivation: $\mathrm{F}<1$; lever $\times$ session $\times$ reactivation: $\left.\mathrm{F}_{(5.4,180)}=1.21, p=0.30\right)$. By contrast, animals that received PRO before reactivation responded less than animals receiving $\mathrm{VEH}$ before reactivation (drug: $\left.\mathrm{F}_{(1,31)}=5.45, p=0.026, \eta^{2}=0.15\right)$ and responded less than animals that received PRO without reactivation (reactivation: $\left.\mathrm{F}_{(1,22)}=9.10, p=0.006, \eta^{2}=0.29\right)$. While non-reactivated, PRO-treated animals responded more on the CS-producing active lever over the course of testing (lever: $\mathrm{F}_{(1,12)}=6.79$, $p=0.023, \eta^{2}=0.36$; lever $\times$ session: $\mathrm{F}_{(3.1,37)}=5.42, p=0.003$, $\eta^{2}=0.31$ ), animals given PRO before reactivation did not bias their responding towards the active lever over the course of testing (lever: $\mathrm{F}_{(1,10)}=2.17, p=0.17$; lever $\times$ session: $\mathrm{F}<1$ ). Thus, systemic propranolol, which readily crosses the bloodbrain barrier, disrupted the reconsolidation of a CS-alcohol memory that subsequently allowed the CS to act as a conditioned reinforcer.

By contrast, administration of the hydrophilic (lipophobic) $\beta$-adrenergic receptor antagonist nadolol, which does not cross the blood-brain barrier, at reactivation did not affect the capacity of the CS to act subsequently as a conditioned reinforcer (Figure $1 \mathrm{~b}$ ), as the reactivated NAD group did not differ in performance from the reactivated VEH group (drug: $F<1$; lever $\times$ drug: $F<1$ ). Therefore, $\beta$-adrenergic receptor antagonism only disrupted the reconsolidation of the CS-alcohol memory if it was administered in conjunction with a memory reactivation session, and if the antagonist was centrally active.

The number of nosepoke responses, which had previously been reinforced with alcohol, did not differ between VEH and PRO groups during ANR testing, as has been observed previously for CS-sucrose and CS-cocaine memo- ries (Supplementary Figure S2). There were no differences between the VEH and PRO groups, regardless of whether drug administration had occurred with memory reactivation or not (drug: $\mathrm{F}<1$; reactivation: $\mathrm{F}_{(1,55)}=3.45, p=0.069$; drug $\times$ reactivation: $\mathrm{F}<1$ ). Interestingly, rats that received NAD before memory reactivation made more nosepokes during the ANR test sessions than the VEH group (drug: $\mathrm{F}_{(1,29)}=5.47, p=0.026, \eta^{2}=0.16$; session $\times$ drug: $\mathrm{F}_{(4.0,117)}=$ 3.97, $\left.p=0.005, \eta^{2}=0.12\right]$. Šidák-corrected pairwise comparisons revealed higher numbers of nosepokes made by the NAD group in the first, second, and fourth ANR test sessions (all $p$ 's $<0.012$ ) but this increased nosepoking was not persistent, and returned to VEH levels from the fifth test session (all p's $>0.16$ ).

Neither propranolol nor nadolol acutely affected performance during the memory reactivation session. Neither of the $\beta$-adrenergic receptor antagonists acutely affected responding during the memory reactivation session (Figure 1d). The number of CS presentations was the same in all reactivated groups (drug: $\mathrm{F}<1$ ) and there were no differences in the numbers of nosepokes made during the memory reactivation session (drug: $\mathrm{F}_{(2,39)}=1.86, p=0.17$ ).

All experimental groups were matched for acquisition of the CS-alcohol association during training. There were no differences between groups in the acquisition of alcoholdrinking behavior as assessed by ethanol consumption during the saccharin-fading procedure (Supplementary Figure S1), and no differences in the acquisition of the CS-alcohol memory during training (Supplementary Figure S3). Rats subsequently given either VEH or PRO on the treatment day did not differ in terms of the amount of ethanol drunk during the saccharin-fading procedure (drug: $\mathrm{F}<1$ ), and there were no differences in ethanol consumption between prospective reactivated and non-reactivated groups (reactivation: $\left.F_{(1,55)}=3.85, p=0.055\right)$. There were no differences in the amount of fluid consumed between the prospective reactivated VEH group and the prospective NAD group (drug: $\mathrm{F}_{(1,29)}=1.24, p=0.28$; session $\times$ drug: $\left.\mathrm{F}<1\right)$.

The prospective VEH and PRO groups were well-matched for performance during nosepoke training (Supplementary Figure S3). All rats acquired the instrumental nosepoke response for ethanol across the course of training (session: $\left.\mathrm{F}_{(4.6,251)}=3.02, \quad p=0.014, \eta^{2}=0.05\right)$ and there were no differences in the number of nosepokes made by the prospective $\mathrm{VEH}$ - or $\mathrm{PRO}$-treated rats (drug: $\mathrm{F}<1$ ) nor any differences between those rats that were subsequently reactivated and those that were not (reactivation: $\mathrm{F}<1$ ). There were also no differences in the number of nosepokes made during training between the prospective reactivated VEH group and the prospective NAD group (drug: $\mathrm{F}<1$ ).

Similarly, there were no differences in the number of CS-alcohol pairings during training. The number of behaviorally contingent CS exposures increased across sessions (session: $\mathrm{F}_{(4.6,255)}=8.16, p<0.001, \eta^{2}=0.13$ ) and there were no differences in the number of nosepokes made by the prospective VEH- or $\mathrm{PRO}$-treated rats $($ drug: $\mathrm{F}<1$ ) nor any differences between those rats that were subsequently reactivated and those that were not (reactivation: $F_{(1,55)}=2.26$, $p=0.14)$. There were also no differences in the number of CS 
exposures during training between the prospective $\mathrm{VEH}$ and NAD groups (drug: $F_{(1,29)}=2.28, p=0.14$ ).

\section{Experiment 2}

Administration of the adrenergic prodrug dipivefrin at reactivation enhanced the capacity of a previously alcoholassociated CS to act subsequently as a conditioned reinforcer. Administration of the adrenergic prodrug DIP before memory reactivation enhanced the capacity of the previously alcohol-associated CS to support the acquisition of a new instrumental response for conditioned reinforcement in subsequent test sessions (drug: $\mathrm{F}_{(1,41)}=4.36$, $\left.p=0.043, \eta^{2}=0.096\right)$. All animals acquired the new instrumental response for conditioned reinforcement (Figure $2 \mathrm{~b}$ and c), discriminating between the CS-producing active lever and the inactive control lever (lever: $\mathrm{F}_{(1,41)}=20.1, p<0.001$, $\left.\eta^{2}=0.33\right)$, with a trend towards slightly better discrimination by the DIP-treated group (lever $\times$ drug: $F_{(1,41)}=3.59$, $p=0.065, \eta^{2}=0.08$ ) and by reactivated animals (lever $\times$ reactivation: $\left.\mathrm{F}_{(1,41)}=4.06, p=0.051, \eta^{2}=0.09\right)$. Although there was no significant interaction of lever $\times$ reactivation $\times$ drug $(\mathrm{F}<1)$, this comparison was somewhat underpowered, with an observed power of 0.14 . However, a priori planned Šidák-corrected pairwise comparisons revealed that animals that received DIP before reactivation responded more on the active lever than VEH-treated controls $(p=0.017)$, while there were no differences between the non-reactivated DIP- and VEH-treated groups $(p=0.339)$. Furthermore, there were no differences in responding on the inactive lever for any of the groups (all p's $>0.62$ ).

There were no differences in the number of nosepokes made during ANR testing (Supplementary Figure S2) by animals treated with DIP or VEH, regardless of whether the drugs were administered before, or in the absence of, memory reactivation (drug: $\mathrm{F}<1$; reactivation: $\mathrm{F}<1$; drug $\times$ reactivation: $\mathrm{F}<1$ ).

Administration of dipivefrin before memory reactivation did not acutely affect behavior during the reactivation session itself. Responding during the memory reactivation session was unaffected by the prior administration of DIP (Figure 2d). There were no differences in the numbers of nosepokes made by the two experimental groups (drug: $\mathrm{F}<1$ ) and consequently no differences in the number of response-contingent CS presentations during reactivation (drug: $\mathrm{F}<1$ ).

All experimental groups were matched for acquisition of the CS-alcohol association during training. There were no differences in the amount of ethanol consumed by the different experimental groups during the saccharin-fading procedure (Supplementary Figure S1). Rats subsequently assigned to the VEH and DIP groups did not differ on the amount of ethanol drunk during fading (drug: $\mathrm{F}<1$ ) and there were no differences between the prospective reactivated and non-reactivated groups (reactivation: $\mathrm{F}_{(1,41)}=2.60$, $p=0.12$ ).

There were no differences between the prospective experimental groups during nosepoke training (Supplementary Figure S3) of the CS-alcohol association (drug:
$\mathrm{F}_{(1,41)}=1.12, \quad p=0.30 ; \quad$ session $\times$ drug: $\quad \mathrm{F}_{(5.1,209)}=1.07$, $p=0.39)$. Although there was a trend towards greater responding in the non-reactivated groups (reactivation: $\left.\mathrm{F}_{(1,41)}=4.01, p=0.052, \eta^{2}=0.09\right)$, this was the case for both the DIP- and VEH-treated groups (drug $\times$ reactivation: $\mathrm{F}<1$; session $\times$ drug $\times$ reactivation: $\mathrm{F}<1$ ). Likewise, there were no differences in the numbers of CS presentations earned during training between the experimental groups, regardless of whether the groups were to be subsequently reactivated or not (drug: $\mathrm{F}<1$; reactivation: $\mathrm{F}_{(1,41)}=1.52$, $p=0.23$; drug $\times$ reactivation: $\mathrm{F}<1$ ).

\section{DISCUSSION}

The experiments described here demonstrate that enhancing and diminishing activity of central $\beta$-adrenergic receptors can bidirectionally modulate the reconsolidation of a CSalcohol memory, as assessed by the capacity of the previously alcohol-associated CS to act as a conditioned reinforcer in rats with a history of alcohol self-administration. As has been observed previously for cocaine-, heroin- and sucroseassociated stimuli (Di Ciano and Everitt, 2004; Parkinson et al, 2005) responding for conditioned reinforcement was persistent and resistant to extinction in vehicle-treated animals. However, the lipophilic $\beta$-adrenergic receptor antagonist propranolol, but not the hydrophilic $\beta$-adrenergic receptor antagonist nadolol, disrupted the reconsolidation of the CS-alcohol memory when administered at memory reactivation. Furthermore, systemic administration of the adrenergic prodrug DIP at reactivation enhanced the reconsolidation of the CS-alcohol memory, increasing the capacity of the previously alcohol-associated CS to act subsequently as a conditioned reinforcer. Thus, these data indicate that the reconsolidation of a CS-alcohol memory can be bidirectionally modulated by reducing and enhancing central adrenergic signaling.

These data extend previous work showing that adrenergic signaling is required for the reconsolidation of the memory underlying conditioned reinforcement for cocaine-associated and sucrose-associated CSs (Milton et al, 2008) through our use of alcohol as the primary reinforcer. Along with the demonstration that propranolol can disrupt the reconsolidation of memories underlying a place preference conditioned to morphine (Robinson and Franklin, 2007) or to alcohol (Wouda et al, 2010), this work shows that adrenergic signaling is not only required for the reconsolidation of memories associated with psychostimulants, but also for drugs with CNS-depressant mechanisms of action. Furthermore, the demonstration that nadolol failed to disrupt the reconsolidation of the CS-alcohol memory adds to growing evidence that central adrenergic signaling is required for memory reconsolidation; the systemic administration of nadolol also failed to disrupt the reconsolidation of the memory underlying morphine-conditioned place preference (CPP) (Robinson and Franklin, 2007), although nadolol administered directly into the basolateral amygdala did disrupt the reconsolidation of the memory underlying cocaine CPP (Otis et al, 2013).

In contrast to previous research, we found that a single treatment of propranolol given at memory reactivation was sufficient to persistently disrupt the CS-US memory for at least 36 days after treatment, whereas multiple reactivation 
and treatment sessions were required to disrupt the reconsolidation of the memory underlying alcohol CPP (Wouda et al, 2010). We have previously shown that propranolol does not disrupt the reconsolidation of the memories underlying alcohol-CS conditioned approach ('sign-tracking') or conditioned motivation (PIT) (Milton et al, 2012). These findings therefore support our hypothesis that propranolol disrupts only one of the three routes to relapse'-that by which drug-associated CSs reinforce drugseeking responses (Milton and Everitt, 2010). It has been shown previously that conditioned approach, conditioned motivation and conditioned reinforcement are supported by different components of the limbic corticostriatal circuitry (see Cardinal et al (2002) for review). Further work will be required to determine whether the capacity of $\beta$-adrenergic signaling to influence memory reconsolidation is reflected by differences in adrenergic projections and receptor distributions in these areas.

The finding that the reconsolidation of a CS-alcohol memory can be enhanced by the administration of the adrenergic prodrug DIP is the first demonstration, to our knowledge, that an appetitive memory has been strengthened by increasing adrenergic signaling at reactivation. Thus, these data extend previous findings for aversive memories, where the administration of the $\beta$-adrenergic receptor agonist isoproterenol (Dębiec et al, 2011) or administration of the $\alpha_{2}$-adrenergic receptor antagonist yohimbine (Gazarini et al, 2013) were shown to enhance the reconsolidation of a CS-fear memory.

Disrupting the memories underlying the three routes to relapse' (Milton and Everitt, 2010) offers an opportunity for improving current treatments to promote abstinence in drug addiction. Of these 'routes to relapse', conditioned reinforcement is particularly problematic because of its persistence and resistance to extinction (Di Ciano and Everitt, 2004). Thus, propranolol may be useful in disrupting the memories that underlie this process in the maladaptive context of addiction. Further work needs to be conducted to determine whether propranolol would be effective in populations with alcohol dependence and whether these results would generalize to previously alcohol-dependent humans, but the finding that a drug that can be safely administered systemically in humans is effective at persistently reducing the risk of relapse in a rodent model of cue-induced relapse holds promise for the development of pro-abstinence, antirelapse treatments for addiction.

\section{ACKNOWLEDGMENTS}

We would like to thank AG Lyon and DE Theobald for technical assistance.

\section{FUNDING AND DISCLOSURE}

This work was supported by a UK Medical Research Council Programme Grant (G1002231) to BJE and ALM and was conducted in the Behavioural and Clinical Neuroscience Institute, an initiative jointly funded by the MRC and the Wellcome Trust. MJWS was supported by an MRC Doctoral Training Grant and the James Baird Fund at the Medical School of the University of Cambridge. ALM was partly supported by a BCNI lectureship and the Ferreras-Willetts Fellowship from Downing College, Cambridge.

\section{AUTHOR CONTRIBUTIONS}

MJWS, ALM and BJE designed the experiments. MJWS and ALM conducted the experiments and analyzed the data. MJWS, ALM and BJE wrote the manuscript. All authors have seen and approved the final version of the manuscript.

\section{REFERENCES}

Anthony JC, Warner LA, Kessler RC (1994). Comparative epidemiology of dependence on tobacco, alcohol, controlled substances, and inhalants: findings from the National Comorbidity Survey. Exp Clin Psychopharmacol 166: 244-268.

Barak S, Liu F, Ben Hamida S, Yowell QV, Neasta J, Kharazia V et al (2013). Disruption of alcohol-related memories by mTORC1 inhibition prevents relapse. Nat Neurosci 16: 1111-1117.

Bliss TVP, Goddard GV, Riives M (1983). Reduction of long-term potentiation in the dentate gyrus of the rat following selective depletion of monoamines. J Physiol 334: 475-491.

Cardinal RN (2000). Whisker Control. www.whiskercontrol.com.

Cardinal RN (2005). Conditioned Reinforcement. www.whiskercon trol.com.

Cardinal RN, Aitken MRF (2006). ANOVA for the Behavioural Sciences Researcher. Lawrence Erlbaum Associates, Inc.: London.

Cardinal RN, Parkinson JA, Hall J, Everitt BJ (2002). Emotion and motivation: the role of the amygdala, ventral striatum, and prefrontal cortex. Neurosci Biobehav Rev 26: 321-352.

Crowe SF, Ng KT, Gibbs ME (1990). Memory consolidation of weak training experiences by hormonal treatments. Pharmacol Biochem Behav 37: 729-734.

Dahl D, Bailey WH, Winson J (1983). Effect of norepinephrine depletion of hippocampus on neuronal transmission from perforant pathway through dentate gyrus. J Neurophysiol 49: 123-133.

de Wit H (1996). Priming effects with drugs and other reinforcers. Exp Clin Psychopharmacol 4: 5-10.

de Wit H, Stewart J (1981). Reinstatement of cocaine-reinforced responding in the rat. Psychopharmacology 75: 134-143.

Dębiec J, Bush DEA, LeDoux JE (2011). Noradrenergic enhancement of reconsolidation in the amygdala impairs extinction of conditioned fear in rats - a possible mechanism for the persistence of traumatic memories in PTSD. Depress Anxiety 28: 186-193.

Dębiec J, LeDoux JE (2004). Disruption of reconsolidation but not consolidation of auditory fear conditioning by noradrenergic blockade in the amygdala. Neuroscience 129: 267-272.

Di Ciano P, Everitt BJ (2004). Conditioned reinforcing properties of stimuli paired with self-adminstered cocaine, heroin or sucrose: implications for the persistence of addictive behavior. Neuropharmacology 47: 202-213.

Diergaarde L, Schoffelmeer ANM, De Vries TJ (2008). Pharmacological manipulation of memory reconsolidation: towards a novel treatment of pathogenic memories. Eur J Pharmacol 585: 453-457.

Erb S, Shaham Y, Stewart J (1996). Stress reinstates cocaine-seeking behavior after prolonged extinction and a drug-free period. Psychopharmacology 128: 408-412.

Escoubet B, Leclercq JF, Maison-Blanche P, Poirier JM, Gourmel B, Delhotal-Landes B et al (1986). Comparison of four beta-blockers as assessed by 24- hour ECG recording. Clin Pharmacol Ther 39: 361-368.

Ferry B, Magistretti PJ, Pralong E (1997). Noradrenaline modulates glutamate-mediated neurotransmission in the rat basolateral amygdala in vitro. Eur J Neurosci 9: 1356-1364. 
Ferry B, Roozendaal B, McGaugh JL (1999). Role of norepinephrine in mediating stress hormone regulation of long-term memory storage: a critical involvement of the amygdala. Biol Psychiatry 46: $1140-1152$.

Font L, Cunningham CL (2012). Post-retrieval propranolol treatment does not modulate reconsolidation or extinction of ethanolinduced conditioned place preference. Pharmacol Biochem Behav 101: 222-230.

Forcato C, Argibay PF, Pedreira ME, Maldonado H (2009). Human reconsolidation does not always occur when a memory is retrieved: the relevance of the reminder structure. Neurobiol Learn Mem 91: 50-57.

Fricks-Gleason AN, Marshall JF (2008). Post-retrieval $\beta$-adrenergic receptor blockade: effects on extinction and reconsolidation of cocaine-cue memories. Learn Mem 15: 643-648.

Gazarini L, Stern CA, Carobrez AP, Bertoglio LJ (2013). Enhanced noradrenergic activity potentiates fear memory consolidation and reconsolidation by differentially recruiting $\alpha_{1^{-}}$and $\beta$-adrenergic receptors. Learn Mem 20: 210-219.

Hatfield T, McGaugh JL (1999). Norepinephrine infused into the basolateral amygdala posttraining enhances retention in a spatial water maze task. Neurobiol Learn Mem 71: 232-239.

Introini-Collison I, McGaugh JL (1986). Epinephrine modulates long-term retention of an aversively motivated discrimination. Behav Neural Biol 45: 358-365.

Introini-Collison I, Saghafi D, Novack GD, McGaugh JL (1992). Memory-enhancing effects of post-training dipivefrin and epinephrine: involvement of peripheral and central adrenergic receptors. Brain Res 572: 81-86.

Kaback MB, Podos SM, Harbin TS Jr, Mandell A, Becker B (1976). The effects of dipivalyl epinephrine on the eye. Am J Ophthalmol 81: 768-772.

Lê AD, Quan B, Juzytch W, Fletcher PJ, Joharchi N, Shaham Y (1998). Reinstatement of alcohol-seeking by priming injections of alcohol and exposure to stress in rats. Psychopharmacology 135: 169-174.

Lee JLC, Everitt BJ (2008). Reactivation-dependent amnesia in pavlovian approach and instrumental transfer. Learn Mem 15: 597-602.

Milton AL (2013). Drink, drugs and disruption: memory manipulation for the treatment of addiction. Curr Opin Neurobiol 23: 706-712.

Milton AL, Everitt BJ (2010). The psychological and neurochemical mechanisms of drug memory reconsolidation: implications for the treatment of addiction. Eur J Neurosci 31: 2308-2319.

Milton AL, Lee JLC, Everitt BJ (2008). Reconsolidation of appetitive memories for both natural and drug reinforcement is dependent on $\beta$-adrenergic receptors. Learn Mem 15: 88-92.

Milton AL, Schramm MJW, Wawrzynski J, Gore F, OikonomouMpegeti F, Wang NQ et al (2012). Antagonism at NMDA receptors, but not $\beta$-adrenergic receptors, disrupts the reconsolidation of pavlovian conditioned approach and instrumental transfer for ethanol-associated conditioned stimuli. Psychopharmacology 219: 751-761.

Otis JM, Dashew KB, Mueller D (2013). Neurobiological dissociation of retrieval and reconsolidation of cocaine-associated memory. J Neurosci 33: 1271-1281.

Parkinson JA, Roberts AC, Everitt BJ, Di Ciano P (2005). Acquisition of instrumental conditioned reinforcement is resistant to the devaluation of the unconditioned stimulus. Q J Exp Psychol B 58: 19-30.
Pedreira ME, Pérez-Cuesta LM, Maldonado H (2004). Mismatch between what is expected and what actually occurs triggers memory reconsolidation or extinction. Learn Mem 11: 579-585.

Robinson MJF, Armson M, Franklin KBJ (2011). The effect of propranolol and midazolam on the reconsolidation of a morphine place preference in chronically treated rats. Front Behav Neurosci 5: 42 .

Robinson MJF, Franklin KBJ (2007). Central but not peripheral beta-adrenergic antagonism blocks reconsolidation for a morphine place preference. Behav Brain Res 182: 129-134.

Robinson MJF, Franklin KBJ (2010). Reconsolidation of a morphine place preference: impact of the strength and age of memory on disruption by propranolol and midazolam. Behav Brain Res 213: 201-207.

Sevenster D, Beckers T, Kindt M (2013). Prediction error governs pharmacologically induced amnesia for learned fear. Science 339: 830-833.

Shaham Y, Stewart J (1996). Effects of opioid and dopamine receptor antagonists on relapse induced by stress and re-exposure to heroin in rats. Psychopharmacology 125: 385-391.

Stanton PK, Sarvey JM (1985). Depletion of norepinephrine, but not serotonin, reduces long-term potentiation in the dentate gyrus of rat hippocampal slices. J Neurosci 5: 2169-2176.

Sternberg DB, Isaacs KR, Gold PE, McGaugh JL (1985). Epinephrine facilitation of appetitive learning: attenuation with adrenergic receptor antagonists. Behav Neural Biol 44: 447-453.

Sternberg DB, Korol D, Novack GD, McGaugh JL (1986). Epinephrine-induced memory facilitation: attenuation by adrenoceptor antagonists. Eur J Pharmacol 129: 189-193.

Théberge FR, Milton AL, Belin D, Lee JLC, Everitt BJ (2010). The basolateral amygdala and nucleus accumbens core mediate dissociable aspects of drug memory reconsolidation. Learn Mem 17: 444-453.

Tiffany ST (1990). A cognitive model of drug urges and drug-use behavior: role of automatic and nonautomatic processes. Psychol Rev 97: 147-168.

Torregrossa MM, Taylor JR (2013). Learning to forget: manipulating extinction and reconsolidation processes to treat addiction. Psychopharmacology 226: 659-672.

UK Home Office (2012). The Government's Alcohol Strategy. The Stationary Office: London.

von der Goltz C, Vengeliene V, Bilbao A, Perreau-Lenz S, Pawlak CR, Kiefer F et al (2009). Cue-induced alcohol seeking behaviour is reduced by disrupting the reconsolidation of alcohol-related memories. Psychopharmacology 205: 389-397.

Wouda JA, Diergaarde L, Riga D, Van Mourik Y, Schoffelmeer ANM, De Vries TJ (2010). Disruption of long-term alcoholrelated memory reconsolidation: role of $\beta$-adrenoceptors and NMDA receptors. Front Behav Neurosci 4: 179.

This work is licensed under a Creative Commons Attribution 4.0 International License. The images article's Creative Commons license, unless indicated otherwise in the credit line; if the material is not included under the Creative Commons license, users will need to obtain permission from the license holder to reproduce the material. To view a copy of this license, visit http://creativecommons.org/licenses/ by/4.0/

Supplementary Information accompanies the paper on the Neuropsychopharmacology website (http://www.nature.com/npp) 